HEALTH HAZARD EVALUATION REPORT 72-28-17

HAZARD EVALUATION SERVICES BRANCH

DIVISION OF TECHNICAL SERVICES

Establishment: Lawndale Industries, Inc.

Lima, Ohio

\author{
Report Prepared By: David J. Burton \\ Industrial Hygiene Engineer \\ Western Area Occupational \\ Heal th Laboratory \\ Jane $A$. Lee \\ Assistant Chief \\ Medical Services Branch \\ Originating Office: Jerome $P$. Flesch \\ Chief, Hazard Evaluation Services Branch \\ Cincinnati, Ohio
}

August 1972

U.S. DEPARTMENT OF HEALTH, EDUCATION, AND WELFARE

NATIONAL INSTITUTE FOR OCCUPATIONAL SAFETY AND HEALTH

CINCINNATI, OHIO 45202 
U.S. DEPARTMENT OF HEALTH, EDUCATION, AND WELFARE

NATIONAL INSTITUTE FOR OCCUPATIONAL SAFETY AND HEALTH

CINCINNATI, OHIO 45202

HEALTH HAZARD EVALUATION REPORT 72-28-17

LAWNDALE INDUSTRIES, IVC.

LIMA, OHIO

AUGUST 1972

\section{SUMMARY DETERMINATION}

Section 20(a)(6) of the 0ccupational Safety and Health Act of 1970, 29 U.S.C. 669(a)(6), authorizes the Secretary of Health, Education, and Welfare, following a written request by any employer or authorized representative of employees, to determine whether any substance normally found in the place of employment has potentially toxic effects in such concentrations as used or found.

The National Institute for Occupational Safety and Health (NIOSH) received such a request from an authorized representative of employees regarding exposure to free silica in milled porcelain enamel.

Respirable free silica concentrations measured on June 8, 1972 at the ground coat spray booth exceeded by approximately three times the established standard (Federal Register, Part II, \$1910.93, Table G-3)

- promulgated by the U.S. Department of Labor to prevent chronic lungdisabling diseases characteristic of such exposure.

Based upon the environmental level of free silica measured and documentation of adverse effects in the literature supporting the standard, it is felt that a hazard to health currently exists in this operation.

Recommendations have been made to management to obviate the observed hazards to the twelve affected employees.

Copies of this Summary Determination as we11 as the Fu11 Report of the evaluation are available from the Hazard Evaluation Services Branch, NIOSH, Cincinnati, Ohio 45202. Copies of both have been sent to:

a) Lawndale Industries, Inc., Lima Plant

b) Authorized Representatives of Employees

c) U.S. Department of Labor - Region V

For purposes of informing "affected employees," the employer will either (1) "post" the Summary Determination in a prominent place near where affected employees work or (2) provide a copy of the determination to each affected employee. 
Page 2 - Health Hazard Evaluation Report 72-23

\section{INTRODUCTION}

Section 20(a)(6) of the Occupational Safety and Health Act of 1970,29 U.S.C. $669(a)(6)$, authorizes the Secretary of Health, Education, and Welfare, following a written request by any employer or authorized representative of employees, to determine whether any substance normally found in the place of employment has potentially toxic effects in such concentrations as used or found.

The National Institute for Occupational Safety and Health (NIOSH) received such a request from an authorized representative of employees regarding exposure to free silica exposures at the porcelain enamel spray areas.

II. BACKGROUND HAZARD INFORMATION

A. Standards

The occupational health standards as promulgated by the U.S. Department of Labor (Federal Register, Part II, \$1910.93, Table G-3) applicable to substances of this evaluation are as follows:

$$
\begin{aligned}
& \text { Nuisance or Inert Dust } \\
& \text { Respirable fraction } \\
& \text { Total dust } \\
& \text { Quartz, Free Silica Bearing Dust } \\
& \text { Respirable fraction }
\end{aligned}
$$

Total dust

$$
\begin{gathered}
5.0 \mathrm{mg} / \mathrm{M}^{3} \\
15.0 \mathrm{mg} / \mathrm{M}^{*}
\end{gathered}
$$

$$
\frac{.10 \mathrm{mg} / \mathrm{m}^{3}}{\% \operatorname{Resp} \cdot \mathrm{S}_{i} \mathrm{O}_{2}+2}
$$

\section{B. Toxic Effects}

Silicosis, the chief silica-caused disease, is produced only by the inhalation of dust containing free silica, which in nature is most frequentiy present in the form of quartz. When carried into the lungs in the form of finely divided dust particles, $5 \mu \mathrm{m}$ or less in diameter, these particles have a devastating effect on lung tissue. Usually the damage occurs very gradually, over a period of years. The usual result is decreased lung capacity and greatly increased susceptibility to tuberculosis.

\footnotetext{
*Units of measurement are: $\mathrm{mg} / \mathrm{M}^{3}$ - milligrams of dust per cubic meter of air.
} 
Page 3 - Health Hazard Evaluation Report 72-28

\section{HEALTH HAZARD EVALUATION}

A. Initial Visit - Observational Survey

A hazard evaluation of the Lima Operations of Lawndale Industries, Inc., subsidiary of Kodial., Inc., was conducted on June 8,1972 by NIOSH representatives Mr. David J. Burton and Jane A. Lee, R.N. The function of the National Institute for Occupational Safety and Health and its relation to Section $20(a)(6)$ of the Occupational Safety and Health Act of 1970 and the purpose of the visit was explained to $\mathrm{Mr}$. General Manager; Mr. , Plant Superintendant; Mr. $\quad$ :, Union Representative; and Mr. Director of Quality Control. The National Surveillance Networ's Part I questionnaire was completed with the assistance of Mr. We were escorted on a walk-through survey of the plant by Messrs.

The Lima Plant of Lawndale Industries is engaged in the manufacture of porcelain-enamel-coated steel bath tubs of various sizes, shapes, and colors.

Stamped bathtub "shapes" are manufactured elsewhere and delivered to the Lima Plant for coating and finishing. Each "shape" is prepared for finishing by cleaning the metal in dip tanks of alkaline soap, clear water, acid, and clear water. The shapes are then carried on overhead conveyor belts to paint booths where they are sprayed with a water-based porcelain enamel called the "ground coat." This coat is then baked on in ovens at about $1500^{\circ} \mathrm{F}$. A finish coat is then applied to the shape and again baked on. Typical ground coat and finish coat compositions are given in Table $I$.

Ground and finish coats are applied by electrostatic spraying in paint booths by men wearing respirators. Approximately 10-12 men are exposed dafly. Mixing of the porcelain takes place in an adjacent area by one man 2 to 3 hours per day. The mix is then milled wet to 200 mesh.

\section{B. Environmental Survey}

Bulk samples of the various constituents were taken. One personnel sample was taken at the ground coat spray booth in the area of highest free silica exposure. Results are given in Tables II and III. Several of the employees were interviewed to determine employee complaints and attitudes regarding environmental conditions. Face velocities at the spray booths were measured. 
Results:

Analysis of the bulk and personnel samples indicate (1) finish coats contained, on an average, less than $1 \%$ free silica, (2) the ground coat contained about $5 \%$ free silica, (3) exposure to respirable free silica at the ground coat spray area was about three times the recommended maximum. It should be noted that this sample was taken on the man most likely to have the highest exposure, the ground coat inside tub sprayer.

Spray booths were well designed, large, and appeared to meet $W$ and $H$ size requirements as specified in Industrial Ventilation, ACGIH, VS-603, (copy in Appendix). Face velocities were measured at about $100 \mathrm{fpm}$.

Shapes moving through the booth are fixed; i.e., they cannot be rotated. This requires the sprayers to periodically stand at the side of the shape while spraying, thus at right angles to the direction of exhaust. All of the observed sprayers were coated with a layer of spray material. Several of the sprayers were not using the electrostatic apparatus while spraying, thus increasing the amount of overspray considerabiy. The ventilation at the exit end of the ground coat booth was observed to be inadequate. A fan located at this spot was spreading ground coat out into the walk-way area.

Coating materials are mixed by hand in large metal containers from bags of raw materials in an adjacent area. No ventilation is provided while mixing.

In the alkaline soap and acid dip tank areas, the acid tank was equipped with exhaust ventilation. No measurements were taken, but the atmosphere obviously contained upper respiratory irritants in considerable amounts.

\section{Medical Survey}

Two employees were interviewed by the occupational health nurse consultant. Both men worked as sprayers. Both complained about lack of sufficient ventilation and other unfavorable work conditions as they perceived them. 
Page 5 - Health Hazard Evaluation Report 72-28

The first man interviewed was about 30 years old, tall, medium build, and had been spraying for about a year. By observing his eyes, nose and ears, it was obvious that the spray-coat had collected on all exposed hair follicles. The nostrils and the outer ear canals were coated with spray. Both eyes demonstrated conjunctivitis, the lower eye lids were red and inflammed, the sclera was slightly injected in both eyes. The employee said he had to lift out particles of the spray from the inner lower lid (cul-de-sac) every night when he showered. He did not wear glasses or safety glasses or goggles. He said he did not feel well several months ago, had chest pains, and had had a chest x-ray which he paid for. He said the $x$-ray was negative.

The second man appeared to be an older man, slightly obese, and had been a sprayer for 18 year's before he came to work at Lawndale Industries two years ago. His respirator had been altered with small pieces of paper towel inserted in the face piece "to keep the sweat out."

Other medical observations noted:

(1) No nursing services are available to employees.

(2) No first-aid stations exist, but first-aid services are available.

(3) Adequate shower and locker room facilities are 1acking.

(4) Periodic physical exams are not company policy.

(5) No forma 1 company program exists for the issuance, inspection, and maintenance of personnel protective equipment.

IV. RECOMMENDATIONS

A. Environmental Recommendations:

Spraying Operations

It is recommended that:

(1) Ground coat spray booth exhaust ventilation should be increased to about 125 FPli face velocity by removing one of the baffling systems.

(2) The fan located at the exit end of the ground coat booth should be removed. 
(3) The electrostatic spray system should not be turned off during spraying.

(4) The drinking fountain located near the cover coat booth should be moved out of the spraying area.

(5) Sprayers should be educated as to:

A. Hazards involved.

B. Positioning of body.

C. Maintenance of personal protective equipment.

Mixing Operations

It is recommended that a small local-exhaust ventilation system be installed at the dry mixing area. A typical system is shown in the appendix.

Shape Cleaning Area

It is recommended that chemical cartridge respirators be made available to workers in this area.

\section{B. Medical Recommendations}

Recognizing the fact that employees are exposed to silica content in the spray-coat by breathing in or ingesting particulates, and also observing that one employee has a chronic eye problem, the following specific recommendations are made:

(1) Pre-employment Chest $x$-ray for all sprayers.

(2) Routine/annual Chest $x$-rays for a 11 sprayers.

(3) Eye examination and consultation for eye care and suggested eye protection for employees sensitive to spray-coat.

(4) Proper placement of employees if any above physical findings are progressive in nature.

C. General Recommendations

Recognizing the fact that employees must be monitored and protected during their working hours from hazards in the work area, the following general recommendations are made: 
Page 7 - Health Hazard Evaluation Report 72-28

(1) Improved facilities to enhance personal hygiene

---locker room

-.--shower room

---drinking fountains (located away from spray-hood)

(2) Eye Wash Fountain (located near spray-hood)

(3) Identifiable First-Aid unit with currently trained first-aiders, and safety instructions for a 11 workers.

(4) Prompt recording of occupational injury and illness.

(5) Adequate emergency care and/or routine care provided for at near-by hospital.

(6) Establishment of a company personal protective clothing and equipment program for all employees exposed to harmful or dangerous processes.

---adequate respirators dependent upon contaminant in air.

---combined face/hood type respirator for employee with eye problem.

---safety glasses or goggles to prevent excessive particles entering eyes.

(7) Improved relations between management and workers as this relates to an effective safety program and safety committee activities with mutually acceptable, reasonable and practical goals and objectives for both. 
TABLE I

GROUND COAT

Material

10840 Chicago Vit. Frit

10104 Chicago Vit. Frit

11006 Chicago Vit. Frit

Silica 400 mesh

$X$ Brand Clay

Q Brand Clay

Magnesium Carbonate

Borax

Bentonite

Potassium Nitrite

Barium Chloride

Water

Fineness of grind 6-8 grams on 200 mesh screen

WHITE COVER COAT

Frit, XT-95

Clay

Bentonite

Potassium Carbonate

Potassium Chloride

Gum

Keltex

Silica

Titanium Dioxide

Zinc oxide

Colors

Water

Ground Coat \% Free Silica $\approx 5 \%$

White Coat $\%$ Free Silica $\cong 7 \%$
Pounds

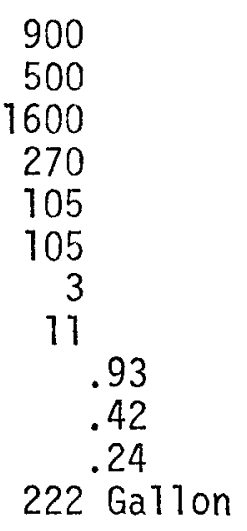

1500

60

4.5

4.65

1.8

0.2

0.2

30

15

7.5

$\sim 3$

95 Gallon 
TABLE II

BULK SAMPLES

Substance

Ferro 400 mesh silica

X-F-57 Frit, K-8018

10380, 10310 Ground Coat Frit

Ground Coat, Prepared

*Not Detected
Analysis, Free Silica Content

100\% free silica

N.D.*

N.D.*

$\sim 10 \%( \pm 5 \%)$ 


\section{TABLE III}

PERSONNEL SAMPLE

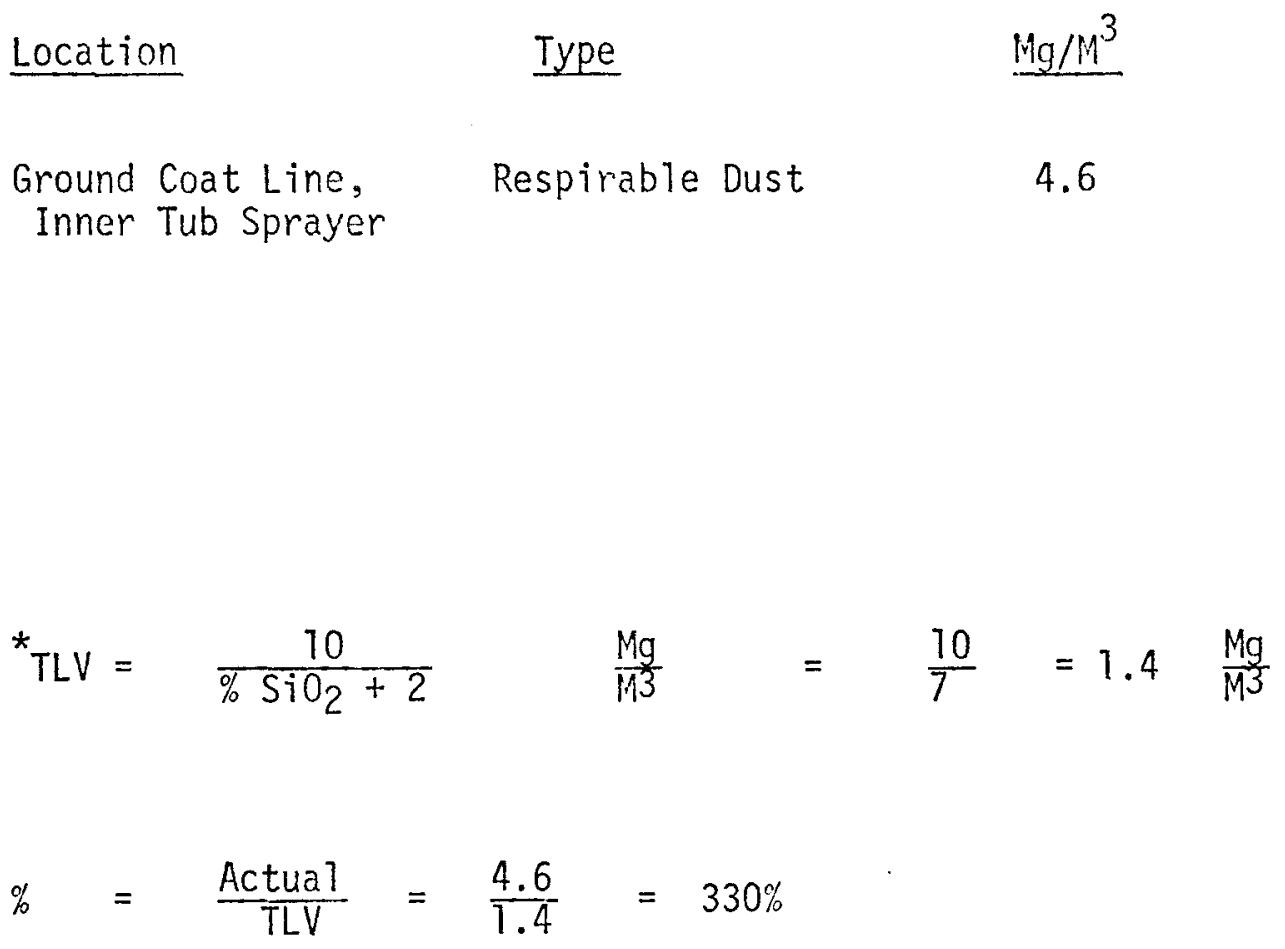

$\%$ of TLV*

330

round Coat Line, 

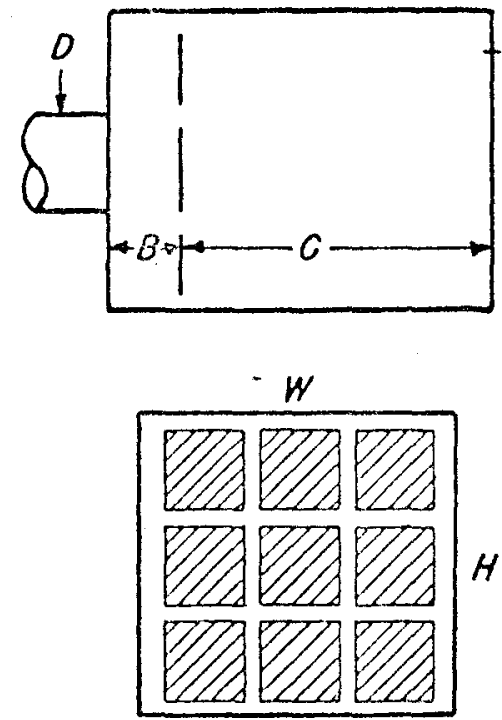

1. Split Baffle or Filters $B=0.750$

Baffle or filter area $=0.75 \mathrm{WH}$

Filfer combustibility Class 2 or better.

Consulf NBFU or insurance underwriters
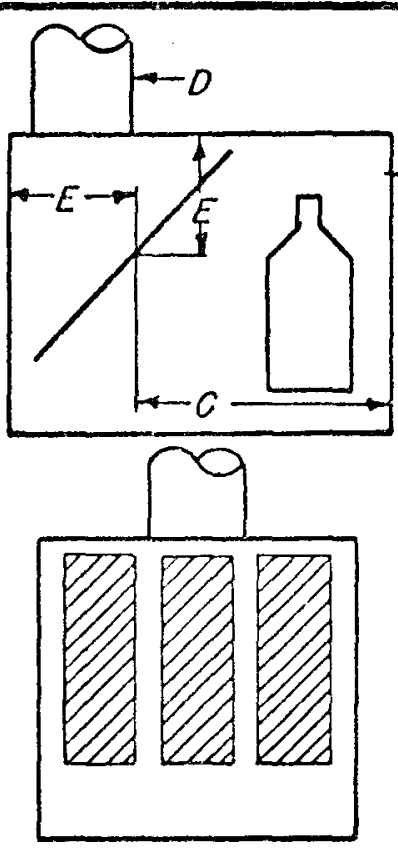

2. Angular Baffle $E=0+6^{\prime \prime}$ Baffle area $=0.40 \mathrm{WH}$

\section{DESIGN DATA}

Any combination of duct connections and baffles moy be used. Large, deep booths do not require baitles. Consuit manufiactures for woier-curioin o'esigns. Use explosion proof fixtures and non-sporking fon. Electrosfatic sproy booth requires autanatic high-volioge disconnasts for conveyor failure, fon foilure or grounding. Consult NBFU.

Walk-in booih

$W=$ work size $+\sigma^{\prime}$

$H=$ work size $+3^{\prime}($ minimum $=7$ )

$C=$ worin size +6

$Q=100 \mathrm{cim} / \mathrm{sq} f \dot{f}$ booth cross section

May be $75 \mathrm{cim} / \mathrm{sq}$ ff for very

lorge, deep, booth. Operator may

require approved respirator.

Entry loss $=0.50$ auct VP +1.78 slot

VP for boffles

$=0.50$ duct VP+ dirty

filter loss
Operator outside booth

$W=$ work size + ?',

$H=$ work size +2

$C=0.75 \times$ larger front dimension

$Q=100-150 \mathrm{cim} / \mathrm{sq} \mathrm{ft}$ of open area, incluoting conveyor openings. 


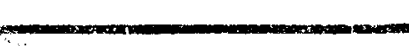

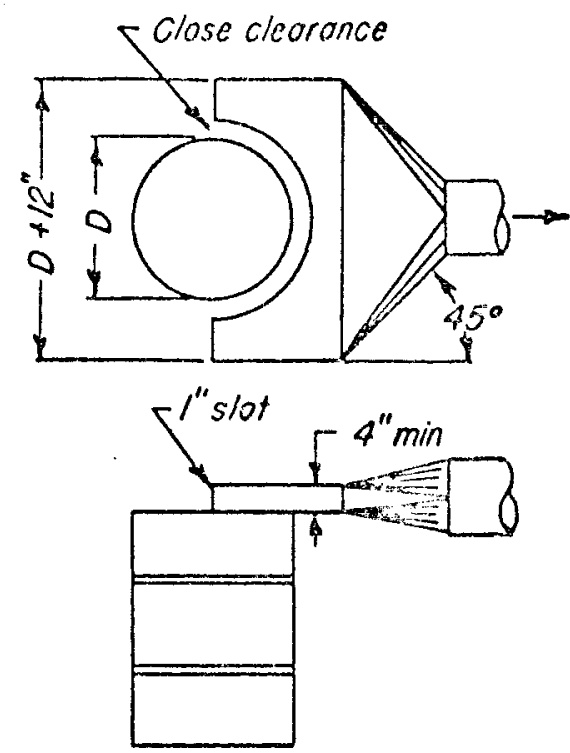

$Q=100 \mathrm{crm} / \mathrm{sq} \mathrm{ft}$ barrel top min

Duct velocity $=3500$ minimum

Entry loss $=0.25$ VF +1.78 slot $\%$

Monual looding.

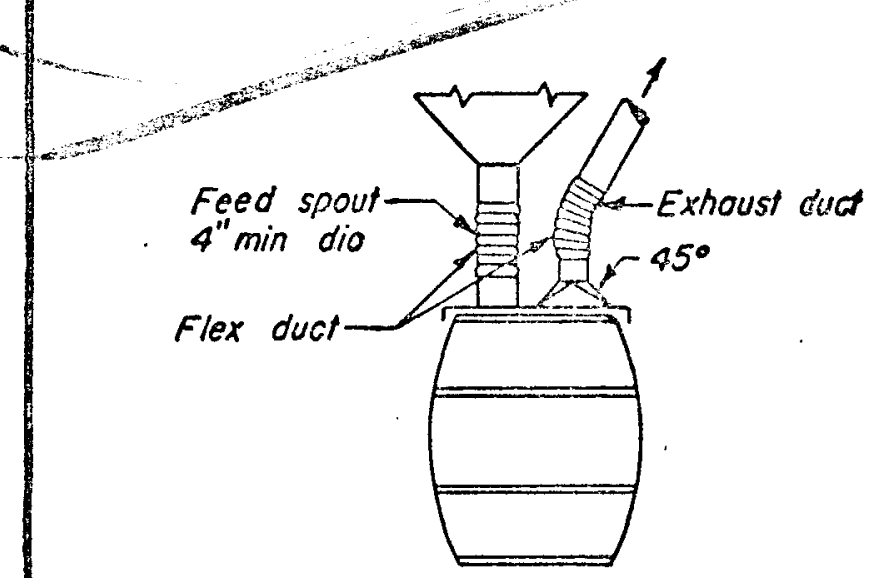

$Q=50 \mathrm{cfm} \times$ drum dia (ft) for weighted lid $150 \mathrm{cfm} \times$ drum dio (ft) for loose lid Duct velocity $=3500 \mathrm{fpm}$ minimum Entry loss $=0.25 \mathrm{VP}$

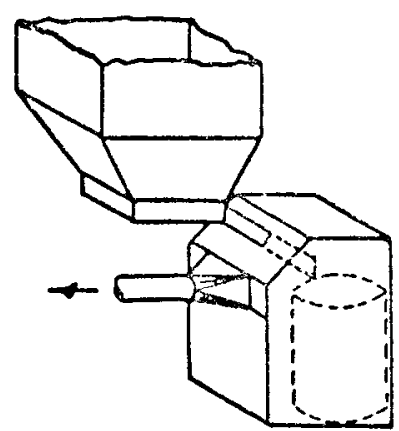

$Q=150 \mathrm{~cm} / \mathrm{sq}$ \&p apen face area Duct velocity $=3500 \mathrm{rom}$ minimum Eniry loss $=0.25 \mathrm{VP}$ for $4.5^{\circ}$ roper
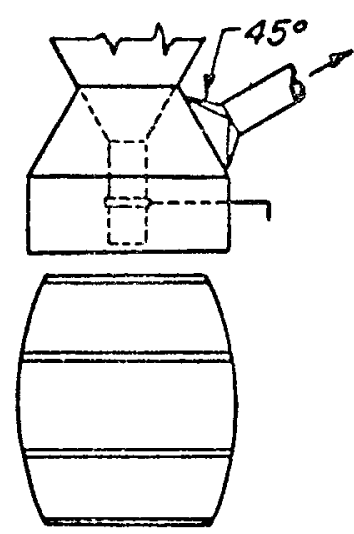

$Q=300.400 \mathrm{cfm}$

Duct velocity $=3500 \mathrm{fom} \mathrm{min}$ Entry loss $=0.25 \mathrm{VP}$
AMERICAN CONFERENCE OF

GOVERNMINTAL INDUSTRIAL HYGIENISTS

BARREL FILLING

\begin{tabular}{ll|l}
\hline DATE & $1-64$ & VS -303 \\
\hline
\end{tabular}


An effective respirator program should 2.1ways accompany the use of respirators.

A good RESPIRATOR PROGRAM contains the following elements:

The RESPIRATOR PROGRAM is administered by a capabTe and responsible person who has a thorough knowledge of the device.

INSPECTION of respirators.

Every respirator should be routinely inspected whether it is used or not. The time interval-every week, 10, 15, 20, or 30 days-- depends on the working conditions.

Inspection includes:

(a) Tightness of connections

(b) Condition of rubber (still pliable, no cracks)

(c) VaTves intact and working

(d) Positioning of filter material - is it airtight?

(e) Headbands working correctly

CLEANING (if respirator is used normaliy by only one individual, day after day.)

A11 respirators should be turned in to a central location and cleaned daily. Each respirator should bear the wearers identification: initials, number, etc. A respirator closet or shelving with each man's respirator in a specific place is good practice.

A quick practical method of cleaning is:

(a) Remove and discard the filter.

(b) Wash in detergent and warm water.

(c) Rinse in clear water.

(d) Air dry in a clean area.

(e) Inspect valves and straps.

(f) Insert new filter pad or material.

(g) Place in respirator closet or in a plastic bag for overnight (or longer) storage.

Storage for long periods of time.

Use dust-proff containers.

Keep away from sunlight, heat, cold, and moisture.

Place respirator in a natural, uncramped, non-twisted position. 